\title{
A pig model of acute right ventricular afterload increase by hypoxic pulmonary vasoconstriction
}

Kathrine Knai ${ }^{{ }^{*}}$ and Nils Kristian Skjaervold ${ }^{2,3}$

\begin{abstract}
Background: The aim of this study was to construct a non-invasive model for acute right ventricular afterload increase by hypoxic pulmonary vasoconstriction. Intact animal models are vital to improving our understanding of the pathophysiology of acute right ventricular failure. Acute right ventricular failure is caused by increased afterload of the right ventricle by chronic or acute pulmonary hypertension combined with regionally or globally reduced right ventricular contractile capacity. Previous models are hampered by their invasiveness; this is unfortunate as the pulmonary circulation is a low-pressure system that needs to be studied in closed chest animals. Hypoxic pulmonary vasoconstriction is a mechanism that causes vasoconstriction in alveolar vessels in response to alveolar hypoxia. In this study we explored the use of hypoxic pulmonary vasoconstriction as a means to increase the pressure load on the right ventricle.

Results: Pulmonary hypertension was induced by lowering the $\mathrm{FiO}_{2}$ to levels below the physiological range in eight anesthetized and mechanically ventilated pigs. The pigs were monitored with blood pressure measurements and blood gases. The mean pulmonary artery pressures (mPAP) of the animals increased from 18.3 (4.2) to 28.4 (4.6) $\mathrm{mmHg}$ and the pulmonary vascular resistance (PVR) from 254 (76) dyns $/ \mathrm{cm}^{5}$ to 504 (191) dyns $/ \mathrm{cm}^{5}$, with a lowering of $\mathrm{FiO}_{2}$ from 0.30 to 0.15 (0.024). The animals' individual baseline mPAPs varied substantially as did their response to hypoxia. The reduced $\mathrm{FiO}_{2}$ level yielded an overall lowering in oxygen offer, but the global oxygen consumption was unaltered.

Conclusions: We showed in this study that the MPAP and the PVR could be raised by approximately $100 \%$ in the study animals by lowering the $\mathrm{FiO}_{2}$ from 0.30 to 0.15 (0.024). We therefore present a novel method for minimally invasive (closed chest) right ventricular afterload manipulations intended for future studies of acute right ventricular failure. The method should in theory be reversible, although this was not studied in this work.
\end{abstract}

Keywords: Acute right ventricular failure, Pulmonary hypertension, Hypoxic pulmonary vasoconstriction

\section{Background}

Heart failure with subsequent circulatory shock is usually ascribed to the left ventricle and the systemic circulation. However, in recent years much attention has been paid to acute right ventricular failure (ARVF) and its contribution to circulatory shock, especially in intensive care medicine [1]. ARVF is most often caused by increased

\footnotetext{
*Correspondence: kathrikn@gmail.com

${ }^{1}$ Department of Circulation and Medical Imaging, Faculty of Medicine, Norwegian University of Science and Technology, Trondheim, Norway Full list of author information is available at the end of the article
}

afterload of the right ventricle (RV) by chronic or acute pulmonary hypertension $(\mathrm{PH})$ combined with regionally or globally reduced contractile capacity of the RV, although ARVF in the absence of $\mathrm{PH}$ is possible [2].

The pulmonary circulation is a low-pressure, low-resistance system. An increase in pulmonary resistance instantaneously raises the RV end-systolic pressure and volume [2-4]. This prolongs the isovolumic contraction, shortens the ejection phase and results in a pumping mechanism similar to that of the left ventricle. The result is both higher oxygen consumption and reduced oxygen supply, 
as coronary perfusion is diminished by elevated intramyocardial pressure. A normal RV can adapt to both chronic and, to a certain degree, acute afterload increases by hypertrophy. However, when the RV fails to compensate for the increased afterload, devastating progressive ARVF and total circulatory breakdown eventually develops.

There is certainly a need for more research on the mechanisms leading to ARVF as well as how to treat the condition [2]. With its complex nature, and because it is caused by relatively small pressure changes, it is important to use good intact animal models to study the phenomenon. Several previous large animal models have used open chest approaches [5-7]. We believe it is vital to keep the chest closed and leave the pericardium intact as these surgical manipulations alter the pressure-flow relations of the RV and the pulmonary circulation, and hence, disturb the ARVF model.

We therefore aimed to construct a new and feasible large animal model where the afterload of the RV could be changed-preferably reversibly-with minimal invasiveness and closed chest. In such a model the hemodynamic effect of increased afterload on RV can be studied in detail, and it would be possible to include this method in different models of RV failure.

In the pulmonary vasculature, vasoconstriction occurs in response to hypoxia, termed hypoxic pulmonary vasoconstriction (HPV). The mechanism acts in response to low alveolar $\mathrm{pO}_{2}$ and is a vital physiological function to direct blood to the ventilated alveoli, and thereby substantially reduce pulmonary shunting. With a decrease in alveolar $\mathrm{pO}_{2}, \mathrm{HPV}$ onsets within seconds [8], increases rapidly and gradually plateaus. The constriction is mainly localized in small resistance pulmonary arteries $(\mathrm{PAs},<200 \mu \mathrm{m})$ [9] and is reversible with restoration of alveolar normoxia. Global hypoxia will induce HPV in all lung segments, resulting in a rise in pulmonary vascular resistance (PVR), with estimates ranging from 50 to $300 \%$ [10]. HPV has been used as a means to increase both acute and chronic PVR in animal experiments [11], but there is no systematic description in the literature on how to use HPV to induce acute RV afterload increase in pigs.

In this study we explored the use of HPV as a means to increase the pressure load on the RV aiming to determine the fraction of inspired oxygen $\left(\mathrm{FiO}_{2}\right)$ level yielding the desired effect without leading to serious dysoxia. We used the standard definition of $\mathrm{PH}$ as a mean pulmonary artery pressure (mPAP) of $\geq 25 \mathrm{mmHg}$ at rest as the target level [12].

\section{Methods}

Animals, handling, anaesthesia, surgery and euthanasia Eight outbred pigs (25\% Duroc, 25\% Yorkshire, 50\% Norwegian Landrace, $29-37 \mathrm{~kg}$ ) were included in the study after approval from the Norwegian State Commission for Animal Experimentation. All the animals received human care in accordance with the European Convention for the Protection of Vertebrate Animals used for Experimental and Other Scientific Purposes.

The animals were premedicated with intramuscular diazepam $10 \mathrm{mg}$ and azaperone $400 \mathrm{mg}$. Anaesthesia was induced through an intravenous access on the external ear with atropine $1.0 \mathrm{mg}$, fentanyl $8.0 \mu \mathrm{g} / \mathrm{kg}$, thiopenthal sodium $4.0 \mathrm{mg} / \mathrm{kg}$ and ketamine hydrochloride $8.0 \mathrm{mg} /$ $\mathrm{kg}$. Before intubation, $5 \mathrm{ml}$ of $40 \mathrm{mg} / \mathrm{ml}$ lidocaine was applied to the larynx. The animals were ventilated in PRVC mode on a Servo-i respirator (Maquet, Getinge Group, Gothenburg, Sweden) with initial values of $\mathrm{FiO}_{2}$ at 0.30 , a tidal volume of $10 \mathrm{ml} / \mathrm{kg}, \mathrm{PEEP}$ at $6 \mathrm{cmH}_{2} \mathrm{O}$ and minute ventilation adjusted to maintain $\mathrm{PaCO}_{2}$ at $4.5-5.5 \mathrm{kPa}$. Anaesthesia was maintained by an infusion of fentanyl $20 \mu \mathrm{g} /(\mathrm{kg} \mathrm{h})$ and midazolam $0.40 \mathrm{mg} /(\mathrm{kg} \mathrm{h})$. Based on clinical response this was supplemented with boluses of fentanyl $50 \mu \mathrm{g} / \mathrm{ml}$ as needed. Intravascular volume was maintained by a bolus of acetated Ringer's solution $10 \mathrm{ml} / \mathrm{kg}$, followed by a continuous infusion of $10 \mathrm{ml} /(\mathrm{kg} \mathrm{h})$ throughout the experiment. $5000 \mathrm{IU}$ heparin was administered i.v. to prevent clot formation.

Before cannulation we surgically prepared the left carotid artery and the right and left internal jugular vein. Two mono lumen catheters were inserted into the left carotid artery and the left internal jugular vein for invasive blood pressure monitoring, arterial blood gases and intravenous injections. A flow-directed pulmonary artery catheter (PAC; Swan Ganz CCOmbo 7.5 Fr, Edwards Lifescience, USA) was inserted in the right internal jugular vein and advanced into the pulmonary artery using classical pressure observations and fluoroscopic guidance and validation. The PAC provided central venous pressure (CVP), pulmonary artery pressure (PAP) and was used to sample mixed venous blood gases. The PAC was connected to a Vigilance II monitor for continuous cardiac output $(\mathrm{CO})$ measurements (Edwards Lifescience, USA). A bladder catheter was inserted by a mini-laparotomy.

At the end of the experiment, the animals were euthanized with pentobarbital $100 \mathrm{mg} / \mathrm{kg}$.

\section{Study protocol and respirator manipulations}

To induce HPV, the $\mathrm{FiO}_{2}$ had to be reduced to levels below the physiological range (the oxygen content in air at sea level is $20.9 \%$, and equals an $\mathrm{FiO}_{2}$ of 0.21 ). In order to reduce the $\mathrm{FiO}_{2}$ to subnormal values, nitrogen was plugged into the air inlet of the respirator, and the animals were then ventilated with an oxygen and nitrogen mixture. The actual $\mathrm{FiO}_{2}$ was monitored via a side stream multi-gas analyser. 
After end of surgery the animals stabilized for $30 \mathrm{~min}$ before baseline measurements were recorded. $\mathrm{PH}$ was then induced by slowly reducing $\mathrm{FiO}_{2}$ on the respirator while monitoring the response in mPAP. When mPAP levels above $25 \mathrm{mmHg}$ were reached, the animal rested for 30 new minutes before new measurements were recorded.

\section{Data material, measurements and statistics}

Vital variables [mean pulmonary artery pressure (mPAP), pulmonary wedged pressure (PWP), central venous pressure (CVP), heart rate (HR), cardiac output $(\mathrm{CO})]$ and arterial and mixed venous blood gases were measured at baseline and after establishing PH. Blood gases were processed by a Radiometer ABL 720 blood gas analyser (Radiometer, Brønshøj, Denmark).

Equations for calculating $\mathrm{PVR}, \mathrm{DO}_{2}$ and $\mathrm{VO}_{2}$ :

Pulmonary vascular resistance (PVR)

$$
=\frac{80(m P A P-P W P)}{C O} \text { Unit: dyn } \mathrm{s} / \mathrm{cm}^{5}
$$

$$
\begin{aligned}
\text { Arterial oxygen content }\left(\mathrm{CaO}_{2}\right)= & (\mathrm{Hgb} \times 1.34) \mathrm{SaO}_{2} \\
+ & \left(\mathrm{PaO}_{2} \times 0.0031\right) \\
& \text { Unit: } \mathrm{ml} \mathrm{O}_{2} / \mathrm{dl} \text { blood }
\end{aligned}
$$

Mixed venous oxygen content $\left(\mathrm{CvO}_{2}\right)$

$$
=(\mathrm{Hgb} \times 1.34) \mathrm{SvO}_{2}+\left(\mathrm{PvO}_{2} \times 0.0031\right)
$$

Oxygen delivery $\left(\mathrm{DO}_{2}\right)=\mathrm{CaO}_{2} \times \mathrm{CO} \times 10$ Unit: $\mathrm{ml} \mathrm{O}_{2} / \mathrm{min}$

Oxygen consumption $\left(\mathrm{VO}_{2}\right)=\mathrm{C}(a-v) \mathrm{O}_{2} \times \mathrm{CO} \times 10$

Only simple descriptive medical statistics and paired sample $t$ tests were used in this study. All datas were analysed in Excel (MS Excel for Mac 2011, Microsoft Corporation, USA) and R (version 3.1.1, The R Foundation for Statistical Computing, Vienna, Austria).

\section{Results}

The individual animals had substantially different baseline mPAP values despite similar age, weight and handling, 18.3 (4.2) $\mathrm{mmHg}$ [mean (sd)] (range 14-27 mmHg). The $\mathrm{FiO}_{2}$ level needed to increase mPAP above $25 \mathrm{mmHg}$ also varied considerably, $0.15(0.026)$ [mean (sd)], range 0.13-0.21. (In the one animal with a baseline mPAP above $25 \mathrm{mmHg}$, the $\mathrm{FiO}_{2}$ was lowered to 0.15 .) This yielded a highly significant overall increase in mPAP from 18.3 (4.2) to 28.4 (4.6) $\mathrm{mmHg}$ ( $\mathrm{p} \ll 0.0001$ ) (Table 1). Since CO did not change, the change in PVR was also consistent in all animals: from $254(76) \mathrm{dyns} / \mathrm{cm}^{5}$ to $504(191)$ dyns $/ \mathrm{cm}^{5}$, yielding a $p$-value of 0.001 (Fig. 1).

Blood gases taken at baseline and after reduction of $\mathrm{FiO}_{2}$ displayed a slight reduction in oxygen delivery $\left(\mathrm{DO}_{2}\right)$ from $409(92) \mathrm{ml} / \mathrm{min}$ to $354(52) \mathrm{ml} / \mathrm{min}$. This was not a statistically significant reduction with a $\mathrm{p}$ value of 0.14. Nor did it affect the oxygen consumption $\left(\mathrm{VO}_{2}\right)$, which remained unchanged, from 195 (35) $\mathrm{ml} / \mathrm{min}$ to 200 (41) $\mathrm{ml} / \mathrm{min}$ (Fig. 2). This was caused by increased oxygen extraction after induction of $\mathrm{PH}$, with a highly significant reduction in mixed venous oxygen saturation $\left(\mathrm{SvO}_{2}\right)$ from $0.51(0.076)$ to $0.36(0.070)$, yielding a $\mathrm{p}$ - value of $\ll 0.0001$ (Fig. 3). Additionally, there were no changes in lactate, $\mathrm{pH}$ or base excess from baseline to after $\mathrm{FiO}_{2}$ reduction. For details, see Additional file 1.

\section{Discussion}

Reduction of $\mathrm{FiO}_{2}$ from 0.3 to 0.15 (0.024) is an efficient

\begin{tabular}{|c|c|c|c|c|c|c|c|c|c|c|}
\hline \multirow[t]{2}{*}{ Pig } & \multicolumn{5}{|c|}{ Baseline (BL) } & \multicolumn{5}{|c|}{ Pulmonary hypertension (PH) } \\
\hline & $\mathrm{FiO}_{2}$ & $\begin{array}{l}\text { mPAP } \\
(\mathrm{mmHg})\end{array}$ & $\begin{array}{l}\text { PWP } \\
(\mathrm{mmHg})\end{array}$ & $\begin{array}{l}\text { CO } \\
(\mathrm{I} / \mathrm{min})\end{array}$ & $\begin{array}{l}\text { PVR } \\
(\text { dyn s/cm5 })\end{array}$ & $\mathrm{FiO}_{2}$ & $\begin{array}{l}\text { mPAP } \\
(\mathrm{mmHg})\end{array}$ & $\begin{array}{l}\text { PWP } \\
(\mathrm{mmHg})\end{array}$ & $\begin{array}{l}\text { CO } \\
(1 / \mathrm{min})\end{array}$ & $\begin{array}{l}\text { PVR } \\
\left(\text { dyn s/cm }{ }^{5}\right)\end{array}$ \\
\hline 1 & 0.30 & 22 & 11 & 3.5 & 251.4 & 0.15 & 34 & 11 & 3.9 & 471.8 \\
\hline 2 & 0.30 & 17 & 7 & 3.2 & 250.0 & 0.21 & 31 & 7 & 4.0 & 480.0 \\
\hline 3 & 0.30 & 17 & 7 & 2.4 & 333.3 & 0.13 & 25 & 7 & 3.0 & 480.0 \\
\hline 4 & 0.30 & 14 & 7 & 2.2 & 254.5 & 0.13 & 25 & 5 & 3.9 & 410.3 \\
\hline 5 & 0.30 & 17 & 7 & 4.5 & 177.8 & 0.14 & 26 & 8 & 4.5 & 320.0 \\
\hline 6 & 0.30 & 15 & 8 & 3.4 & 164.7 & 0.14 & 25 & 8 & 2.9 & 469.0 \\
\hline 7 & 0.30 & 27 & 6 & 4.3 & 390.7 & 0.15 & 36 & 6 & 2.5 & 960.0 \\
\hline 8 & 0.30 & 17 & 9 & 3.0 & 213.3 & 0.15 & 25 & 9 & 2.9 & 441.4 \\
\hline
\end{tabular}
method for increasing the afterload of the RV, yielding an overall doubling of the PVR. The effect took place in all animals and should therefore be considered a reliable

Table 1 Changes in mPAP, PWP and PVR from baseline to pulmonary hypertension

Both mPAP and PVR increase with reduction of $\mathrm{FiO}_{2}$ and globally induced hypoxic pulmonary vasoconstriction

$\mathrm{FiO}_{2}$ fraction of inspired oxygen, $M P A P$ mean pulmonary arterial pressure, $P W P$ pulmonary wedged pressure, $C O$ cardiac output, $P V R$ pulmonary vascular resistance 


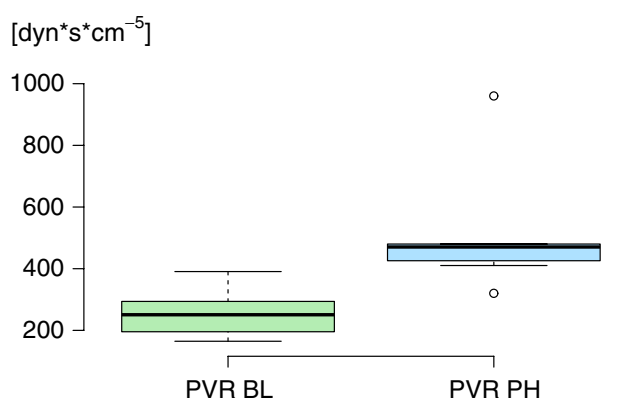

Fig. 1 Changes in PVR from baseline to pulmonary hypertension. The overall increase in PVR from baseline to pulmonary hypertension is approximately $100 \%$, with a p-value of 0.001 . PVR BL pulmonary vascular resistance at baseline, $P V R P H$ pulmonary vascular resistance at pulmonary hypertension

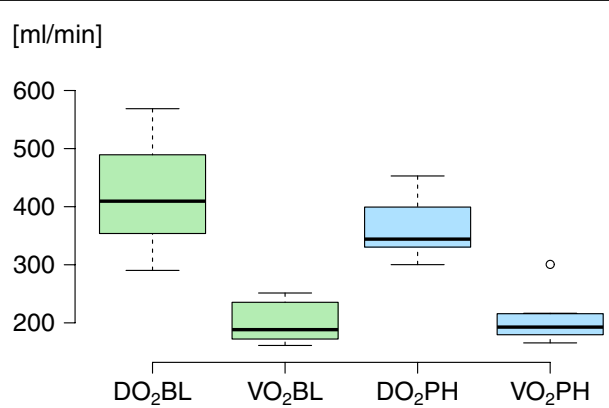

Fig. 2 Changes in oxygen delivery and consumption from baseline to pulmonary hypertension. Neither $\mathrm{DO}_{2}$ nor $\mathrm{VO}_{2}$ changed with the reduction of $\mathrm{FiO}_{2}$ indicating minor disturbance to the model. $\mathrm{DO}_{2} \mathrm{BL}$ oxygen delivery at baseline, $\mathrm{VO}_{2} \mathrm{BL}$ oxygen consumption at baseline, $\mathrm{DO}_{2} \mathrm{PH}$ oxygen delivery at pulmonary hypertension, $\mathrm{VO}_{2} \mathrm{PH}$ oxygen consumption at pulmonary hypertension

general physiological feature. As such, this method can be used in future studies of RV adaption to increased afterload; the combination with some method of regional or global RV contractility reduction should in theory induce ARVF (Additional file 1: Table S1).

There was considerable variation in individual animals' baseline mPAPs and the $\mathrm{FiO}_{2}$ reduction needed for a sufficient mPAP increase. One could therefore ask whether this kind of model should aim at increasing the mPAP (or $\mathrm{PVR}$ ) above a clinical definition of $\mathrm{PH}$, as was done in this study, or whether one should aim for a relative change in afterload in each respective animal, say, a $100 \%$ increase in mPAP (or PVR) from baseline. Either way, the $\mathrm{FiO}_{2}$ reduction has to be adapted to the individual animal.

Some animals experienced a relatively large reduction of arterial oxygen saturation $\left(\mathrm{SaO}_{2}\right)$ as a consequence of the $\mathrm{FiO}_{2}$ reduction, leading to decreased $\mathrm{DO}_{2}$ overall. This did not lead to a decreased $\mathrm{VO}_{2}$ because of an increased oxygen extraction. It should be noted, however,

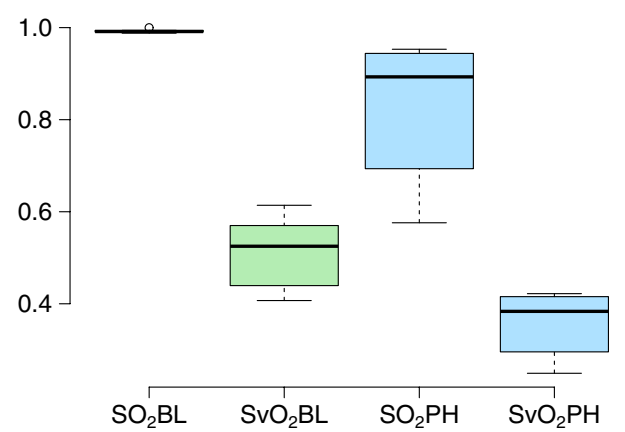

Fig. $3 \mathrm{SO}_{2}$ and $\mathrm{SvO}_{2}$ before and after decreased $\mathrm{FiO}_{2}$. There was some reduction with a large spread in $\mathrm{SO}_{2}$, and a large and significant change in $\mathrm{SvO}_{2}$ from baseline to pulmonary hypertension

that this occurred in the stable situation $30 \mathrm{~min}$ after establishing the lower $\mathrm{FiO}_{2}$ value (Fig. 2). We noticed during the initial phase of $\mathrm{FiO}_{2}$ reduction a transient change in skin colour and a decline in plethysmographic measured $\mathrm{SaO}_{2}$. After some minutes with their new oxygen supply, the animals regained their previous colour and $\mathrm{SaO}_{2}$ level. This immediate physiological instability after serious system perturbations followed by stabilization after a few minutes is an interesting physiological feature that we have also experienced in other animal models.

Another word of caution is that in some of the pilot animals prior to this study, we lowered the $\mathrm{FiO}_{2}$ too rapidly to levels that were too low, yielding an extremely low $\mathrm{SvO}_{2}$. This is a very strong stimulus to the sympathetic nervous system, leading to tachycardia and a high $\mathrm{CO}$ to compensate for the hypoxia. The pulmonary circulation is constructed to be able to receive large volumes of blood without increasing the pulmonary arterial pressure. This is mainly caused by an increase of the total cross-sectional area of the pulmonary vasculature, resulting from passive distension and recruitment of collapsed vessels [13]. In this situation the animals ended up with an increased mPAP from baseline, but with the same or even a reduced PVR. It is therefore important to be very careful when using our method, because it approaches the limit of the animal's ability to compensate.

In theory, this method of increasing mPAP and PVR by reducing $\mathrm{FiO}_{2}$ should be fully reversible. Unfortunately, we did not study whether the mPAP returned to its baseline value after re-establishing normal $\mathrm{FiO}_{2}$, or the time frame needed for this to occur. In the literature, HPV is described as biphasic with one rapid and one late phase. The time aspect is inconclusively described with variations in onset and duration for both phases [10, 13-15]. The long phase is said to last from $45 \mathrm{~min}$ to several hours, but there are no conclusive descriptions of 
how long the hypoxia must be maintained for this phase to kick in, nor how fast the vascular tone is returned to normal with restoration of normoxia. This emphasizes the need for further investigation of the method's reversibility.

This study was not designed to investigate RV changes as a consequence of increased afterload. In accordance with the theory as described in the background, increased afterload itself should not be enough to cause failure in a healthy RV. This was also our impression during the study, as CVP remained unchanged and $\mathrm{CO}$ didn't show any systematically decrease. However, a full assessment of RV's adaption to changing loading conditions requires assessment with conductance catheters or similar in order to extract pressure-volume loops $[6,11]$.

Resistance as defined in practical clinical medicine and in this manuscript as a measure of afterload is an application of Ohm's law where resistance $=\Delta$ pressure/flow. In reality, this is only valid for a system of linear flow. In the pulmonary (and systemic) circulation, flow is oscillatory, in which impedance is a better calculation of the overall afterload. The continuous flow and pressure signals are assessed by Fourier analyzes and then the pressure/flow relations are compared for the respective harmonics [16]. Thus, in order to examine impedance, high-resolution continuous pressure and flow signals are mandatory, which we did not have in this study.

\section{Conclusion}

We showed in this study that the mPAP and the PVR could be raised by approximately $100 \%$ in the study animals by lowering the $\mathrm{FiO}_{2}$ from 0.30 to 0.15 (0.024). The responses were individual, as were the baseline mPAPs. This $\mathrm{FiO}_{2}$ reduction led to reduced $\mathrm{SaO}_{2}$ and hence $\mathrm{DO}_{2}$ in some animals, but the $\mathrm{VO}_{2}$ was not reduced after a stabilization period. We note that in the initial phase, the animals seemed to be unstable, with clinical signs of dysoxia, but they regained normal oxygenation after some minutes. Furthermore, this method should be used with some caution, as reducing $\mathrm{FiO}_{2}$ too rapidly might lead to sympathetic nervous activation with tachycardia and high CO, resulting in a secondary normalization of PVR despite high mPAP. The method should in principle be reversible, although we did not study this in this work. We therefore present a novel method for minimal-invasive (closed chest) RV afterload manipulations intended for future studies of ARVF.

\section{Additional file}

Additional file 1: Table S1. Arterial and mixed venous blood gases at baseline and pulmonary hypertension.

\section{Abbreviations}

ARVF: acute right ventricular failure; RV: right ventricle; $\mathrm{PH}$ : pulmonary hypertension; HPV: hypoxic pulmonary vasoconstriction; $\mathrm{FiO}_{2}$ : fraction of inspired oxygen; PAC: pulmonary artery catheter; PAP: pulmonary artery pressure; PWP: pulmonary wedged pressure; CVP: central venous pressure; HR: heart rate; CO: cardiac output; PVR: pulmonary vascular resistance; $\mathrm{DO}_{2}$ : oxygen delivery; $\mathrm{VO}_{2}$ : oxygen consumption.

\section{Authors' contributions}

KK and NKS participated in the planning and carrying out of the experimental part of the study. KK drafted the manuscript. NKS performed the statistical analysis and contributed to revising the manuscript. Both authors read and approved the final manuscript.

\section{Author details \\ ${ }^{1}$ Department of Circulation and Medical Imaging, Faculty of Medicine, Nor- wegian University of Science and Technology, Trondheim, Norway. ${ }^{2}$ Depart- ment of Circulation and Medical Imaging, Norwegian University of Science and Technology, Trondheim, Norway. ${ }^{3}$ Department of Anaesthesia and Inten- sive Care Medicine, Trondheim University Hospital, Trondheim, Norway. \\ Acknowledgements \\ This work was supported by research grants from the Faculty of Medicine, Norwegian University of Science and Technology and Department of Anaes- thesia and Intensive Care Medicine, Trondheim University Hospital. \\ We would like to thank Oddveig Lyng for her contribution to the experi- mental part of the study.}

\section{Competing interests}

The authors declare that they have no competing interests.

\section{Ethical approvals and consent to participate}

Approval was obtained from the Norwegian State Commission for Animal Experimentation. All the animals received human care in accordance with the European Convention for the Protection of Vertebrate Animals used for Experimental and Other Scientific Purposes.

Received: 26 January 2016 Accepted: 10 December 2016 Published online: 03 January 2017

\section{References}

1. Greyson CR. Right heart failure in the intensive care unit. Curr Opin Crit Care. 2012;18:424-31.

2. Greyson CR. Pathophysiology of right ventricular failure. Crit Care Med. 2008;36(1 Suppl):S57-65.

3. Mebazaa A, Karpati P, Renaud E, Algotsson L. Acute right ventricular failure-from pathophysiology to new treatments. Intensive Care Med. 2004;30:185-96.

4. Price LC, Wort SJ, Finney SJ, Marino PS, Brett SJ. Pulmonary vascular and right ventricular dysfunction in adult critical care: current and emerging options for management: a systematic literature review. Crit Care. 2010;14:R169.

5. Barer GR, Howard P, Shaw JW. Stimulus-response curves for the pulmonary vascular bed to hypoxia and hypercapnia. J Physiol. 1970;211:139-55.

6. Yerebakan C, Klopsch C, Niefeldt S, Zeisig V, Vollmar B, Liebold A, Sandica $\mathrm{E}$, Steinhoff $\mathrm{G}$. Acute and chronic response of the right ventricle to surgically induced pressure and volume overload - an analysis of pressurevolume relations. Interact CardioVasc Thorac Surg. 2010;10:519-25.

7. Chua J, Zhou W, Ho JK, Patel NA, Mackensen GB, Mahajan A. Acute right ventricular pressure overload compromises left ventricular function by altering septal strain and rotation. J Appl Physiol. 2013;115:186-93.

8. Jensen KS, Micco AJ, Czartolomna J, Latham L, Voelkel NF. Rapid onset of hypoxic vasoconstriction in isolated lungs. J Appl Physiol. 1985;1992(72):2018-23. 
9. Anand IS. Hypoxia and the pulmonary circulation. Thorax. 1994;49(Suppl):S19-24.

10. Moudgil R, Michelakis ED, Archer SL. Hypoxic pulmonary vasoconstriction. J Appl Physiol. 2005;98:390-403.

11. Wauthy P. Right ventricular adaptation to pulmonary hypertension: an interspecies comparison. AJP Heart Circ Physiol. 2003;286:H1441-7.

12. Task Force for Diagnosis and Treatment of Pulmonary, Hypertension of European Society of Cardiology (ESC), European Respiratory Society (ERS), International Society of Heart and Lung Transplantation (ISHLT), Galiè N, Hoeper MM, Humbert M, Torbicki A, Vachiery J-L, Barbera JA, Beghetti M, Corris P, Gaine S, Gibbs JS, Gomez-Sanchez MA, Jondeau G, Klepetko W, Opitz C, Peacock A, Rubin L, Zellweger M, Simonneau G. Guidelines for the diagnosis and treatment of pulmonary hypertension. Eur Respir J. 2009;34:1219-63.
13. Lumb AB. Nunn's applied respiratory physiology. London: Elsevier Health Sciences; 2012.

14. Swenson ER. Hypoxic pulmonary vasoconstriction. High Alt Med Biol. 2013;14:101-10.

15. Lumb AB, Slinger P. Hypoxic pulmonary vasoconstriction: physiology and anesthetic implications. Anesthesiology. 2015;122:932-46.

16. Westerhof N, Noble MIM. Snapshots of Hemodynamics: an aid for clinical research and graduate education. New York: Springer Science \& Business Media; 2010

\section{Submit your next manuscript to BioMed Central and we will help you at every step:}

- We accept pre-submission inquiries

- Our selector tool helps you to find the most relevant journal

- We provide round the clock customer support

- Convenient online submission

- Thorough peer review

- Inclusion in PubMed and all major indexing services

- Maximum visibility for your research

Submit your manuscript at www.biomedcentral.com/submit 